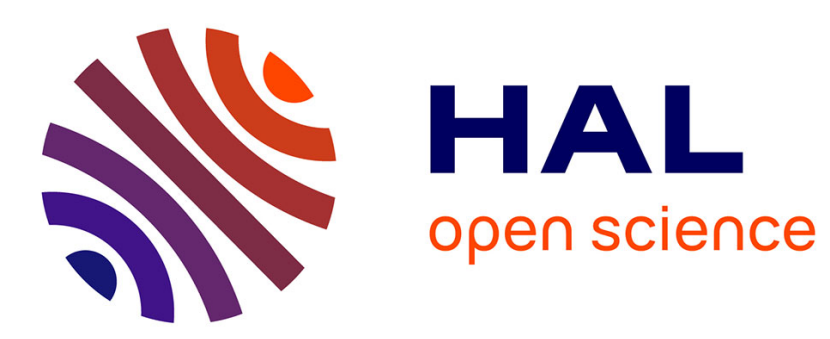

\title{
High-throughput RNAi screening to dissect cellular pathways: a how-to guide
}

Christina Falschlehner, Sandra Steinbrink, Gerrit Erdmann, Michael Boutros

\section{To cite this version:}

Christina Falschlehner, Sandra Steinbrink, Gerrit Erdmann, Michael Boutros. High-throughput RNAi screening to dissect cellular pathways: a how-to guide. Biotechnology Journal, 2010, 5 (4), pp.368. 10.1002/biot.200900277. hal-00552340

\section{HAL Id: hal-00552340 https://hal.science/hal-00552340}

Submitted on 6 Jan 2011

HAL is a multi-disciplinary open access archive for the deposit and dissemination of scientific research documents, whether they are published or not. The documents may come from teaching and research institutions in France or abroad, or from public or private research centers.
L'archive ouverte pluridisciplinaire HAL, est destinée au dépôt et à la diffusion de documents scientifiques de niveau recherche, publiés ou non, émanant des établissements d'enseignement et de recherche français ou étrangers, des laboratoires publics ou privés. 


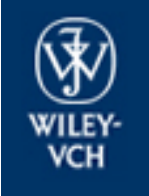

Biotechnology Journal

\section{High-throughput RNAi screening to dissect cellular pathways: a how-to guide}

\begin{tabular}{|c|c|}
\hline Journal: & Biotechnology Journal \\
\hline Manuscript ID: & biot.200900277.R1 \\
\hline Wiley - Manuscript type: & Review \\
\hline $\begin{array}{r}\text { Date Submitted by the } \\
\text { Author: }\end{array}$ & 19-Feb-2010 \\
\hline Complete List of Authors: & $\begin{array}{l}\text { Falschlehner, Christina; DKFZ, Signaling and Functional Genomics - } \\
\text { B110 } \\
\text { Steinbrink, Sandra; DKFZ, Signaling and Functional Genomics } \\
\text { Erdmann, Gerrit; DKFZ, Signaling and Functional Genomics } \\
\text { Boutros, Michael; DKFZ, Signaling and Functional Genomics }\end{array}$ \\
\hline Primary Keywords: & Methods \\
\hline Secondary Keywords: & RNA interference \\
\hline Keywords: & RNA interference, high-throughput, screening \\
\hline
\end{tabular}

\section{scholaroNE \\ Manuscript Central}




\title{
Research Article ((5178 words)) \\ High-throughput RNAi screening to dissect cellular pathways: a how-to guide
}

\author{
Christina Falschlehner, Sandra Steinbrink, Gerrit Erdmann and \\ Michael Boutros \\ German Cancer Research Center and University of Heidelberg, Div. \\ Signaling and Functional Genomics, D-69120 Heidelberg, Germany
}

\begin{abstract}
RNA interference (RNAi) has become a powerful tool to dissect cellular pathways and characterize gene functions. The availability of genome-wide RNAi libraries for various model organisms and mammalian cells has enabled high-throughput RNAi screenings. These RNAi screens successfully identified key components that had previously been missed in classical forward genetic screening approaches and allowed the assessment of combined loss-of-function phenotypes. Crucially, the quality of RNAi screening results depends on quantitative assays and the choice of the right biological context. In this review, we provide an overview on the design and application of high-throughput RNAi screens as well as data analysis and candidate validation strategies.
\end{abstract}

\section{Introduction}

In the past, reverse genetic techniques have successfully been used to identify and characterize gene functions. One of the most powerful tools in functional genomics emerged from the discovery of RNAi.

RNAi is a sequence-specific, post-transcriptional silencing process that is mediated by double-stranded RNA (dsRNA) molecules [1]. RNAi is a widespread cellular process that can be found in fungi, plants and animals. It is thought that RNAi has evolved as a defence mechanism to eliminate dsRNA from viruses. In recent years, RNAi has also been implicated in the regulation of transposons and in the formation and maintenance of heterochromatic regions in the genome [2$6]$.

The RNAi mechanism can be induced by endogenous microRNAs (miRNAs) encoded in the genome or by exogenous dsRNAs that have been introduced into the cell by viruses (shRNA) or synthetic experimental interventions [7, 8]. In mammalian cells, the transcription of an endogenously encoded miRNA leads to the formation of a hairpin-shaped RNA molecule, which is processed by the nuclease Drosha. The resulting pre-miRNA is transported from the nucleus into the cytoplasm and further processed by the RNase III-family member DICER into smaller fragments, typically between 21 and 23 nucleotides (nts) long, named 
small interfering RNAs (siRNAs). Such siRNAs can also be chemically synthesized and artificially introduced, for example by transient liposome-based transfections. These RNAs are then incorporated into the RNA-induced silencing complex (RISC) where they serve as templates to recognize and pair to their complementary mRNAs [9]. Mature miRNAs preferentially bind to the 3' UTR whereas most synthetic siRNAs target the open reading frame. In case of a perfect match, the mRNA is cleaved and degraded rapidly whereas imperfect matching results in translational repression and destabilization of the respective mRNA (see Figure 1). The decrease in gene expression as a consequence of reduced mRNA level is referred to as a "knockdown". If synthetic siRNAs are designed to target the $3^{\prime} U T R$, the rescue construct can be designed without the 3'UTR, becoming "immune" to the siRNAs.

In recent years systematic screens employing RNAi have become a powerful technique for studying gene function in various model organisms. The availability of RNAi-reagent libraries covering full genomes allows high-throughput analysis of single gene functions as well as characterization of functional gene clusters and dissection of cellular signaling networks.

Model organisms, such as Caenorhabditis elegans and Drosophila melanogaster have proved successful for the application of large-scale RNAi screens in vivo and in cultured cell lines [11-14]. In C. elegans, RNAi can be performed by injecting dsRNA [1], by soaking worms in a solution of dsRNA [15], or by feeding Escherichia coli (E.coli) that express target-gene dsRNA [16]. In Drosophila, RNAi can be triggered by long dsRNAs, which are taken up very efficiently by cultured cells from the cell culture medium after a short starvation period [17]. In addition, in vivo fly libraries are available that express RNAi reagents under tissue or time-specific promoters and allow for the analysis of the RNAi effect in the whole animal $[18,19]$.

In mammalian cells, the application of long dsRNA induces a strong interferon response [20, 21]. Therefore, other strategies for RNA-induced gene silencing have to be applied. To date, genome-wide libraries targeting the human genome with short dsRNA molecules can be obtained from different sources and in various formats. These libraries usually contain pools of three to four independent siRNAs or several independent single sequences targeting one mRNA to increase the likelihood of a successful knockdown. In addition, endoribonucleolytically digested small overlapping dsRNA fragments (esiRNAs) and small hairpin RNA libraries (shRNAs) encoded on vector backbones can be used for systematic knockdown analysis [10, 22]. Chemically synthesized siRNAs and esiRNAs are introduced into the cells by liposomal transfection, electroporation or by linking RNAs to guiding peptides [9, 23-26]. These siRNAs can be further chemically modified to increase stability and transfection efficiency [27-29]. Furthermore, lenti-, retro- or adenoviral particles carrying DNA vectors that encode shRNAs can be used to transduce mammalian cells that are difficult to transfect with other methods [10, 30, 31]. Viral RNAi constructs can be used to easily generate cell lines stably expressing the knockdown construct. Thus, 
persistent loss of a gene product enables monitoring of the knockdown over longer time periods allowing the analysis of many relevant biological questions.

\section{High-throughput RNAi screening}

Systematic RNAi screenings can be used to elucidate a biologically relevant question that is reflected in the assay system of interest. For a precise and meaningful result, this question needs to be well-defined, supplemented with a carefully chosen read-out system, followed by an accurate and optimized technical screening procedure. Special care should be taken when choosing the read-out system. The system needs to be technically stable and robust to avoid misleading background noise, but sensitive enough to detect subtle changes in the analysed setting. In general, assays that are straightforward are easier to handle and to control. The more complex an assay system is, the more controls are needed to check for stability and correctness. Common read-out options to analyse a variety of biological questions are the following:

Cellular viability: Several assay types based on the detection of fluorescence, luminescence as well as absorption, are available. Cellular viability is often correlated by quantifying ATP levels (e.g. CellTiterGlo, Promega), esterase activity and membrane integrity (e.g. Calcein-AM, Sigma) or cellular redox potential (e.g. WST-1/MTT, Sigma).

Cell morphology: (Immuno)fluorescent staining of cellular features such as cytoskeleton, DNA and different organelles allows the parallel and automated analysis of various cellular phenotypes with image analysis software. The clustering of high-content phenotypic data can be used to generate so called 'phenoprints' that characterize the individual knockdowns.

Reporter assay: Fluorescence- or chemoluminescence-based assays in which the activity of a signaling pathway or biological network can be investigated. Usually, a transcription-factor binding site for a pathway-specific transcriptionfactor is coupled to a reporter gene driven by a minimal promoter. These assays can be either conducted using transient transfections or cell lines stably expressing the reporter constructs.

Functional assays: A wide variety of functional assays can be used to assess different cellular events and can be based on different read-outs (e.g. caspase activity, $\mathrm{Ca}^{+}$signaling).

In addition, many of the above mentioned assays can be combined or modified to answer different questions or to draw further conclusions (combinatorial RNAidrug treatment, viability assessment of morphology screens by DNA content quantification, and combinatorial viability and reporter screens).

A further decision has to be made on the model organism to use for the screen. Human cultured cell lines offer the possibility to dissect the full human genome for various processes e.g. those that are disturbed in different diseases. In certain cases it might be advantageous to make use of model organisms such as 
C. elegans or Drosophila. The RNAi procedure in worms and cultured fly cells is relatively cheap and easy and the dissection of conserved signaling pathways or biological processes is often more successful in identifying novel pathway mediators due to a low genetic redundancy in these organisms. Furthermore, when analysing complex biological questions such as behaviour or developmental processes, the use of whole animal systems for screening is indispensable. Nevertheless, full organism screens, especially in Drosophila flies, are laborious and time consuming and the use of cultured cells is preferable to facilitate the throughput and handling complexity.

When using human cells, the selection of the cell line has to be considered carefully. Classical cultured cell lines, such as human embryonic kidney (HEK293T) or cervix carcinoma (HeLa) cells are often used for genome-wide RNAi screens as they are easy to grow and to transfect with siRNAs. However, the use of these cell lines is probably not the right choice to analyse specific biological procedures such as T- or B-cell receptor signaling. The right cell line should always be defined by the biological question to answer. Such initial considerations are crucial as they may predetermine the significance and relevance of potential screening hits.

The biological question also determines the choice of the RNAi library. The options include distinct subset libraries, for instance kinase or phosphatase libraries, libraries covering the "druggable" genome or genome-wide libraries. A collection of different available RNAi libraries is given in Table 1.

\section{((Table 1))}

The use of siRNA pools, usually consisting of 3-4 single siRNA sequences, versus the use of individual siRNAs is another choice to make [44]. On the one hand, siRNA pools are likely to increase the knockdown efficiency and reduce off-target effects due to the relatively lower concentration of the individual siRNAs in the respective pool. On the other hand, the use of individual siRNA sequences in a screen might facilitate hit evaluation as it enables target selection on the condition that at least two or more individual siRNAs directed against the respective gene show the same phenotype. The latter approach, however, multiplies the consumption of materials and the time necessary to conduct a screen. Thus, the final decision of which system to use also involves cost and time considerations.

Before conducting a genome-wide screen, the screening approach has to be evaluated on a small scale. For the pilot screen, a subset of randomly selected genes that represent the respective library as well as positive and negative controls have to be defined. These controls are an absolute requirement for the reliance of the screen. The results of the pilot screen will allow conclusions to be drawn on assay stability, robustness of controls and the overall dynamic range. Performing a pilot screen will also help identify bottlenecks in the screening procedure that may have to be optimized for a genome-wide screening protocol. A common quality criterion for high-throughput RNAi screens is the Z'-factor that describes the variability and the dynamic range of the assay between the positive 
and negative controls. A stable assay should result in a Z'-factor between 0.5 and 1 to enable the separation of hits from the background noise [45].

The final scale of the RNAi screen should be taken into consideration when calculating reagent amounts, incubator space, equipment area, handling times and batch sizes based on the results of the pilot screen. Additional time spent on optimizations at this stage will pay off in terms of data quality in the subsequent large-scale screen. Especially, efforts spent on the miniaturization of the assay system later on save time and money and often improve the stability of the system and therefore the data quality. Most assay types conducted in human cultured cell lines can be done in 384-well high-density cell culture plates. For smaller Drosophila cells 1536-well plates are feasible. To avoid variations during handling of those plates, the screening procedure should be automated in most steps. The screen itself is done relatively fast even on a genome-wide scale. Care should be taken to avoid every possible variation between plate and batch handling, the use of different reagent lots, and incubation periods.

\section{Analysis of RNAi screening data}

The analysis of raw data from a screen can be complex and time consuming. Computational data analysis methods are commonly used to normalize the data and to correct for e.g. plate position effects and batch to batch variations. Specific software solutions can be applied for normalization of the screen and for supplying an initial hit list of the strongest phenotypes (e.g. cellHTS, Spotfire/Tibco). cellHTS, a software package based on the programming language $\mathrm{R}$ and the opensource platform Bioconductor (www.bioconductor.org) was specifically designed to analyze RNAi screens capturing both workflow and data analysis [46]. In 2009, a web-based version of cellHTS was launched allowing for online data analysis (http://web-cellhts2.dkfz.de).

The analysis of genome-wide RNAi screens will result in a gene list with an associated list of z-scores. These scores describe the difference in standard deviations between a given value and the median of all values [47]. The range of z-scores will be large and the values for positive and negative controls should be nicely separable from each other (see Figure 2). A high z-score reflects a significant deviation of a phenotype from the median of a screen. Moderate phenotypes, reflected by lower z-scores, can be caused by an incomplete knockdown of a gene with a strong effect or by a strong knockdown of a gene with a weak phenotype.

For analysis of microscopy-based imaging screens, open source software packages such as CellProfiler (www.cellprofiler.org; [48]), EBImage (www.bioconductor.org/packages/bioc/1.9/html/EBImage.html), and DetecTIFF (www.detectiff.com; [49] ) are available. These software tools analyse cell count and shape phenotypes as well as specific changes in staining levels created by antibody or dye staining of certain cellular events. Cells are identified and analysed for a variety of parameters, which are collected and saved as specific 
phenotypic fingerprints of each phenotype. These phenotypic clusters can be used to identify novel gene functions by similarity analysis. However, storage of large-scale datasets, especially of microscopy-based imaging screens that can easily exceed a terabyte per screen remains challenging.

Depending on what the actual read-out of the screen is, several artefacts can occur and need to be corrected if possible. The most common are plate position effects such as edge, row and column effects. Edge effects usually derive from evaporation from assay plates. Artefacts can also arise due to chemicals used in a screen carried over from liquid handling steps or a poor chemical or biological stability of reagents over time. Most of these effects should be eliminated during the optimization procedure, others can be minimized by, for example, reserving an incubator exclusively for a screen, using so-called plate hotels/stackers and avoiding small volumes of liquid when possible. Plate position and other effects can be visualised by different software tools (e.g. cellHTS, Spotfire) and can be corrected by fitting functions that model these effects. Other artefacts can be harder or impossible to correct, thus leading to the exclusion of individual wells or plates from the screen (e.g. signaling decay of some luciferases). The final output of the initial data analyses is a list of the strongest hits in the screen, which can comprise of up to several dozens potential candidates.

\section{Retests and secondary assays}

To validate the phenotype of candidate genes found in an RNAi screen a comprehensive retesting strategy should be applied. This is necessary because RNAi can cause sequence-dependent and -independent off-target effects, meaning that not the candidate gene, but another (unknown) gene is responsible for the observed phenotype. Sequence-dependent off-targets can occur when the siRNA sense instead of the antisense strand is incorporated into the RISC and subsequently mediates silencing of non-targeted genes. The siRNA antisense strand can also partially match to another mRNA sequence consequently cause silencing of non-targeted genes. Sequence-independent offtarget effects mostly originate from liposomal transfection procedures, from stimulation of pathways associated with the immune response and from saturating the endogenous RNAi machinery [50].

The initial analysis of genome-wide RNAi screening data leads to a long list of candidate genes that are ranked according to their z-scores reflecting the strength of the phenotype. To validate these phenotypes as a consequence of candidate gene silencing and not silencing of an unintended gene, multiple independent siRNA sequences should be used, which target the same gene at different locations in the mRNA sequence [51]. When a library of pooled siRNAs was used during the screening procedure, the candidate pools should be deconvoluted into single sequences. In addition, the gene phenotype can be confirmed with RNAi reagents from different vendors that target the respective mRNA at different sites. Furthermore, the knockdown efficiency of single siRNAs 
should be validated using qRT-PCR or immunoblotting and correlated with the observed phenotype (see Figure $3 A$ and $B$ ). Candidate gene phenotypes should at least be reproducible with two independent RNAi reagents.

The most reliable way of excluding off-target effects is by substituting the silenced gene with an RNAi-insensitive expression construct, reverting the RNAi phenotype. In the case of a long candidate gene list, this approach is rather laborious and time-consuming as the respective expression constructs have to be cloned first. Nevertheless, the phenotype of previously evaluated top-ranked candidates should finally be confirmed using this method.

Thus, several different strategies are commonly used to reduce initial hit lists depending on the screen type. Usually, the initial hits are retested with the same assay as used in the large-scale screen to eliminate false positives.

Secondary small-scale screens are often conducted using a different assay that elucidates the same biological question to eliminate false positives that are related to the specificity of the primary assay and to provide a hit list of highly probable candidates for further studies. Therefore a number of secondary assays can be performed that validate the phenotype with methods independent to those used in the screen. These assays should be specific for the question addressed by the screen thus eliminating unspecific hits. There is a wide variety of secondary assays that can be performed, for example microscopy-based translocation assays or immunoblot analysis (see Figure $3 \mathrm{C}$ and $\mathrm{D}$ ).

After retesting and phenotype validation the candidate screen list will be shortened and improved. Finally, the remaining candidates can be investigated further to find their exact mechanism of action in the respective signaling pathway(s). A summary of the high-throughput RNAi procedure, including all essential screening steps described in the review, is given in Figure 4.

\section{Outlook}

During recent years, the identification of numerous novel gene functions have shown that genome-wide RNAi screens are a valuable tool for the analysis of various biological processes and the dissection of signaling pathways. Data sets resulting from these experiments are now being collected and compared in databases, enabling a systems biology approach which gives insight into the regulation of complex cellular signaling networks (http://www.genomernai.org). The collection of phenotypic parameters enables the clustering of genes according to the similarity of their phenotypes and the subsequent interpretation of putative related functions. Used in combination with drugs, systematic RNAi approaches can help unravel the mode of action of drugs, identify enhancers of the therapeutic mechanism or shed light on putative markers of resistance of a certain treatment [52-54]. Thus, RNAi screens might help in the near future to improve the treatment of highly resistant and aggressive tumours by identifying targets for efficient cotreatments [55-58]. 
The authors acknowledge support by the Helmholtz Alliance for Systems Biology.

The authors have declared no conflict of interest.

\section{References}

[1] Fire, A., Xu, S., Montgomery, M. K., Kostas, S. A., et al., Potent and specific genetic interference by double-stranded RNA in Caenorhabditis elegans. Nature 1998, 391, 806-811.

[2] Aliyari, R., Ding, S. W., RNA-based viral immunity initiated by the Dicer family of host immune receptors. Immunol Rev 2009, 227, 176-188.

[3] Pal-Bhadra, M., Bhadra, U., Birchler, J. A., RNAi related mechanisms affect both transcriptional and posttranscriptional transgene silencing in Drosophila. $\mathrm{Mol}$ Cell 2002, 9, 315-327.

[4] Tabara, H., Sarkissian, M., Kelly, W. G., Fleenor, J., et al., The rde-1 gene, RNA interference, and transposon silencing in C. elegans. Cell 1999, 99, 123132.

[5] van Rij, R. P., Berezikov, E., Small RNAs and the control of transposons and viruses in Drosophila. Trends Microbiol 2009, 17, 163-171.

[6] Volpe, T., Schramke, V., Hamilton, G. L., White, S. A., et al., RNA interference is required for normal centromere function in fission yeast. Chromosome Res 2003, 11, 137-146.

[7] Fedorov, Y., King, A., Anderson, E., Karpilow, J., et al., Different delivery methods-different expression profiles. Nat Methods 2005, 2, 241.

[8] Whitehead, K. A., Langer, R., Anderson, D. G., Knocking down barriers: advances in siRNA delivery. Nat Rev Drug Discov 2009, 8, 129-138.

[9] Elbashir, S. M., Harborth, J., Lendeckel, W., Yalcin, A., et al., Duplexes of 21nucleotide RNAs mediate RNA interference in cultured mammalian cells. Nature 2001, 411, 494-498.

[10] Brummelkamp, T. R., Bernards, R., Agami, R., Stable suppression of tumorigenicity by virus-mediated RNA interference. Cancer Cell 2002, 2, 243247.

[11] Bartscherer, K., Pelte, N., Ingelfinger, D., Boutros, M., Secretion of Wnt ligands requires Evi, a conserved transmembrane protein. Cell 2006, 125, 523533.

[12] Boutros, M., Kiger, A. A., Armknecht, S., Kerr, K., et al., Genome-wide RNAi analysis of growth and viability in Drosophila cells. Science 2004, 303, 832-835.

[13] Fraser, A. G., Kamath, R. S., Zipperlen, P., Martinez-Campos, M., et al., Functional genomic analysis of $\mathrm{C}$. elegans chromosome I by systematic RNA interference. Nature 2000, 408, 325-330.

[14] Gonczy, P., Echeverri, C., Oegema, K., Coulson, A., et al., Functional genomic analysis of cell division in $\mathrm{C}$. elegans using RNAi of genes on chromosome III. Nature 2000, 408, 331-336. 
[15] Tabara, H., Grishok, A., Mello, C. C., RNAi in C. elegans: soaking in the genome sequence. Science 1998, 282, 430-431.

[16] Timmons, L., Fire, A., Specific interference by ingested dsRNA. Nature 1998, 395, 854.

[17] Clemens, J. C., Worby, C. A., Simonson-Leff, N., Muda, M., et al., Use of double-stranded RNA interference in Drosophila cell lines to dissect signal transduction pathways. Proc Natl Acad Sci U S A 2000, 97, 6499-6503.

[18] Kambris, Z., Brun, S., Jang, I. H., Nam, H. J., et al., Drosophila immunity: a large-scale in vivo RNAi screen identifies five serine proteases required for Toll activation. Curr Biol 2006, 16, 808-813.

[19] Dietzl, G., Chen, D., Schnorrer, F., Su, K. C., et al., A genome-wide transgenic RNAi library for conditional gene inactivation in Drosophila. Nature 2007, 448, 151-156.

[20] Manche, L., Green, S. R., Schmedt, C., Mathews, M. B., Interactions between double-stranded RNA regulators and the protein kinase DAI. Mol Cell Biol 1992, 12, 5238-5248.

[21] Stark, G. R., Kerr, I. M., Williams, B. R., Silverman, R. H., Schreiber, R. D., How cells respond to interferons. Annu Rev Biochem 1998, 67, 227-264.

[22] Kittler, R., Buchholz, F., Functional genomic analysis of cell division by endoribonuclease-prepared siRNAs. Cell Cycle 2005, 4, 564-567.

[23] Gresch, O., Engel, F. B., Nesic, D., Tran, T. T., et al., New non-viral method for gene transfer into primary cells. Methods 2004, 33, 151-163.

[24] Muratovska, A., Eccles, M. R., Conjugate for efficient delivery of short interfering RNA (siRNA) into mammalian cells. FEBS Lett 2004, 558, 63-68.

[25] Brazas, R. M., Hagstrom, J. E., Delivery of small interfering RNA to mammalian cells in culture by using cationic lipid/polymer-based transfection reagents. Methods Enzymol 2005, 392, 112-124.

[26] Kittler, R., Putz, G., Pelletier, L., Poser, I., et al., An endoribonucleaseprepared siRNA screen in human cells identifies genes essential for cell division. Nature 2004, 432, 1036-1040.

[27] Birmingham, A., Anderson, E., Sullivan, K., Reynolds, A., et al., A protocol for designing siRNAs with high functionality and specificity. Nat Protoc 2007, 2, 2068-2078.

[28] Deleavey, G. F., Watts, J. K., Damha, M. J., Chemical modification of siRNA. Curr Protoc Nucleic Acid Chem 2009, Chapter 16, Unit 1613.

[29] Ge, Q., Dallas, A., Ilves, H., Shorenstein, J., et al., Effects of chemical modification on the potency, serum stability, and immunostimulatory properties of short shRNAs. RNA, 16, 118-130.

[30] Rubinson, D. A., Dillon, C. P., Kwiatkowski, A. V., Sievers, C., et al., A lentivirus-based system to functionally silence genes in primary mammalian cells, stem cells and transgenic mice by RNA interference. Nat Genet 2003, 33, 401406.

[31] Meacham, C. E., Ho, E. E., Dubrovsky, E., Gertler, F. B., Hemann, M. T., In vivo RNAi screening identifies regulators of actin dynamics as key determinants of lymphoma progression. Nat Genet 2009, 41, 1133-1137. 
[32] Kamath, R. S., Ahringer, J., Genome-wide RNAi screening in Caenorhabditis elegans. Methods 2003, 30, 313-321.

[33] Kamath, R. S., Fraser, A. G., Dong, Y., Poulin, G., et al., Systematic functional analysis of the Caenorhabditis elegans genome using RNAi. Nature 2003, 421, 231-237.

[34] Sonnichsen, B., Koski, L. B., Walsh, A., Marschall, P., et al., Full-genome RNAi profiling of early embryogenesis in Caenorhabditis elegans. Nature 2005, 434, 462-469.

[35] Hild, M., Beckmann, B., Haas, S. A., Koch, B., et al., An integrated gene annotation and transcriptional profiling approach towards the full gene content of the Drosophila genome. Genome Biol 2003, 5, R3.

[36] Gilsdorf, M., Horn, T., Arziman, Z., Pelz, O., et al., GenomeRNAi: a database for cell-based RNAi phenotypes. 2009 update. Nucleic Acids Res, 38, D448-452.

[37] Foley, E., O'Farrell, P. H., Functional dissection of an innate immune response by a genome-wide RNAi screen. PLoS Biol 2004, 2, E203.

[38] Berns, K., Hijmans, E. M., Mullenders, J., Brummelkamp, T. R., et al., A large-scale RNAi screen in human cells identifies new components of the p53 pathway. Nature 2004, 428, 431-437.

[39] Paddison, P. J., Silva, J. M., Conklin, D. S., Schlabach, M., et al., A resource for large-scale RNA-interference-based screens in mammals. Nature 2004, 428, 427-431.

[40] Reynolds, A., Leake, D., Boese, Q., Scaringe, S., et al., Rational siRNA design for RNA interference. Nat Biotechnol 2004, 22, 326-330.

[41] Silva, J. M., Li, M. Z., Chang, K., Ge, W., et al., Second-generation shRNA libraries covering the mouse and human genomes. Nat Genet 2005, 37, 12811288.

[42] Huesken, D., Lange, J., Mickanin, C., Weiler, J., et al., Design of a genomewide siRNA library using an artificial neural network. Nat Biotechnol 2005, 23, 995-1001.

[43] Giuliano, K. A., Haskins, J. R., Taylor, D. L., Advances in high content screening for drug discovery. Assay Drug Dev Technol 2003, 1, 565-577.

[44] Parsons, B. D., Schindler, A., Evans, D. H., Foley, E., A direct phenotypic comparison of siRNA pools and multiple individual duplexes in a functional assay. PLoS One 2009, 4, e8471.

[45] Zhang, J. H., Wu, X., Sills, M. A., Probing the primary screening efficiency by multiple replicate testing: a quantitative analysis of hit confirmation and false screening results of a biochemical assay. J Biomol Screen 2005, 10, 695-704.

[46] Boutros, M., Bras, L. P., Huber, W., Analysis of cell-based RNAi screens. Genome Biol 2006, 7, R66.

[47] Larsen, R. J., Marx, M. L., An Introduction to Mathematical Statistics and Its Application. Third Edition. ISBN 0139223037. 2000, 282.

[48] Carpenter, A. E., Jones, T. R., Lamprecht, M. R., Clarke, C., et al., CellProfiler: image analysis software for identifying and quantifying cell phenotypes. Genome Biol 2006, 7, R100. 
[49] Gilbert, D. F., Meinhof, T., Pepperkok, R., Runz, H., DetecTiff: a novel image analysis routine for high-content screening microscopy. J Biomol Screen 2009, 14, 944-955.

[50] Martin, S. E., Caplen, N. J., Applications of RNA interference in mammalian systems. Annu Rev Genomics Hum Genet 2007, 8, 81-108.

[51] Echeverri, C. J., Beachy, P. A., Baum, B., Boutros, M., et al., Minimizing the risk of reporting false positives in large-scale RNAi screens. Nat Methods 2006, 3, 777-779.

[52] Barbie, D. A., Tamayo, P., Boehm, J. S., Kim, S. Y., et al., Systematic RNA interference reveals that oncogenic KRAS-driven cancers require TBK1. Nature 2009, 462, 108-112.

[53] Whitehurst, A. W., Bodemann, B. O., Cardenas, J., Ferguson, D., et al., Synthetic lethal screen identification of chemosensitizer loci in cancer cells. Nature 2007, 446, 815-819.

[54] Aza-Blanc, P., Cooper, C. L., Wagner, K., Batalov, S., et al., Identification of modulators of TRAIL-induced apoptosis via RNAi-based phenotypic screening. Mol Cell 2003, 12, 627-637.

[55] Lopez-Fraga, M., Martinez, T., Jimenez, A., RNA interference technologies and therapeutics: from basic research to products. BioDrugs 2009, 23, 305-332.

[56] Dykxhoorn, D. M., RNA interference as an anticancer therapy: a patent perspective. Expert Opin Ther Pat 2009, 19, 475-491.

[57] Kassner, P. D., Discovery of novel targets with high throughput RNA interference screening. Comb Chem High Throughput Screen 2008, 11, 175-184. [58] Lee, A. J., Kolesnick, R., Swanton, C., RNAi-mediated functional analysis of pathways influencing cancer cell drug resistance. Expert Rev Mol Med 2009, 11, e15. 
Table 1: Collection of available RNAi libraries

\begin{tabular}{|c|c|c|c|}
\hline Description & Reference/Supplier & Organisms & Links \\
\hline $\begin{array}{l}\text { RNAi feeding library } \\
\text { (87\% genome } \\
\text { coverage) }\end{array}$ & [13]; [32, 33] & C. elegans & $\begin{array}{l}\text { www.gurdon.cam.ac.uk/ ahrin } \\
\text { gerlab/pages/rnai.html }\end{array}$ \\
\hline $\begin{array}{l}\text { RNAi library for } \\
\text { injection }\end{array}$ & [14]; [34] & C. elegans & $\begin{array}{l}\text { www.worm.mpi- } \\
\text { cbg.de/phenobank2 }\end{array}$ \\
\hline $\begin{array}{l}\text { Long dsRNA library } \\
\text { ( } 21,306 \text { PCR } \\
\text { templates) }\end{array}$ & [35] & Drosophila & www.flyrnai.org \\
\hline $\begin{array}{l}\text { Genome-wide dsRNA } \\
\text { library (DRSC) }\end{array}$ & [12] & Drosophila & www.flyrnai.org \\
\hline $\begin{array}{l}\text { Genome-wide dsRNA } \\
\text { library }\end{array}$ & {$[36]$} & Drosophila & http://rnai.dkfz.de \\
\hline Long dsRNA library & {$[37]$} & Drosophila & $\frac{\text { http://www.openbiosystem.co }}{\underline{\mathrm{m}}}$ \\
\hline $\begin{array}{l}\text { Non-mammalian } \\
\text { subset libraries }\end{array}$ & $\begin{array}{l}\text { Distributed by } \\
\text { Open Biosystems }\end{array}$ & $\begin{array}{l}\text { Drosophila, } \\
\text { C.elegans, } \\
\text { Arabidopsis } \\
\text { thaliana, } \\
\text { Zebrafish } \\
\text { morpholinos }\end{array}$ & www.openbiosystems.com \\
\hline esiRNA library & {$[26]$} & Human & $\begin{array}{l}\text { www.mpi- } \\
\underline{\text { cbg.de/esiRNA/index.html }}\end{array}$ \\
\hline $\begin{array}{l}\text { shRNA library } \\
\text { (TRC1/2) }\end{array}$ & $\begin{array}{l}\text { Distributed by } \\
\text { Sigma and Open } \\
\text { Biosystems }\end{array}$ & Human & www.broadinstitute.org/rnai/trc \\
\hline $\begin{array}{l}\text { NKI shRNA library } \\
\text { (targeting } 8000 \\
\text { genes, retroviral) }\end{array}$ & [38] & Human & http://www.screeninc.nl \\
\hline $\begin{array}{l}\text { Library of retroviral } \\
\text { vectors }\end{array}$ & [39] & Human & http://codex.cshl.edu \\
\hline $\begin{array}{l}\text { Genome-wide siRNA } \\
\text { library, subset } \\
\text { libraries e.g. kinases, } \\
\text { phosphatases }\end{array}$ & Dharmacon; [40] & $\begin{array}{l}\text { Human, } \\
\text { Mouse }\end{array}$ & www.dharmacon.com \\
\hline $\begin{array}{l}\text { Genome-wide shRNA } \\
\text { library }\left(\text { GeneNet }{ }^{\mathrm{TM}}\right)\end{array}$ & $\begin{array}{l}\text { System } \\
\text { Biosciences }\end{array}$ & $\begin{array}{l}\text { Human, } \\
\text { Mouse }\end{array}$ & www.systembio.com \\
\hline $\begin{array}{l}\text { shRNA-mir library } \\
\text { (retroviral) }\end{array}$ & {$[41]$} & $\begin{array}{l}\text { Human, } \\
\text { Mouse }\end{array}$ & \\
\hline $\begin{array}{l}\text { Genome-wide siRNA } \\
\text { library, subset } \\
\text { libraries }\end{array}$ & Qiagen; [42] & $\begin{array}{l}\text { Human, } \\
\text { Mouse, Rat }\end{array}$ & www.qiagen.com \\
\hline
\end{tabular}


Genome-wide siRNA Ambion; [43] Human, www.ambion.com library, subset

Mouse, Rat, libraries

Drosophila

(subset) 
Figure 1: Schematic view of RNAi in mammalian cells. Endogenous microRNAs (miRNA) and exogenous small hairpin RNAs (shRNA) are transcribed from DNA by RNA polymerase II. The resulting RNA hairpin is then processed by the nuclease Drosha, resulting in premiRNA/processed shRNA which is transported from the nucleus into the cytoplasm via exportin 5 (Exp5). The RNA is further processed into $\sim 21 \mathrm{bp}$ fragments by the ribonuclease DICER. Synthetic short-interfering RNAs (siRNAs) resemble DICER processed double-stranded RNAs. These RNAs are incorporated into the RNA-induced silencing complex (RISC) where they are unwound and bind to complementary mRNA. Mature miRNAs preferentially bind to the 3' UTR while most siRNAs target the open reading frame. In case of a perfect match, the mRNA is cleaved and degraded. In contrast, imperfect matching leads to translational repression and consequent mRNA destabilization $[9,10]$.

Figure 2: Scatter plot of average z-scores from a genome-wide RNAi screen. Luciferase reporter activity was measured using Mithras LB940 plate reader (Berthold Technologies) and TOPflash (TCF reporter plasmid). Cell viability was determined using Calcein-AM. siRNAs targeting b-catenin that result in reduction of wnt reporter activity were used as positive control. siRNAs targeting UBC cause loss of cell viability and were used as viability control. Non-targeting siRNAs were used as negative control.

Figure 3: Hit validation with retests and secondary assays. A) Phenotype scores of control, single siRNAs and corresponding siRNA pool. B) Matching qRT-PCR validating knockdown of control, single siRNAs and corresponding siRNA pool. C) Nuclear translocation assay showing localization of the wnt pathway component $\beta$-catenin upon signal cascade activation by RNAi (scale bars equal $10 \mu \mathrm{m}$ ). D) Western blot analysis indicating knockdown of $\beta$-catenin on protein level.

Figure 4: Schematic view of the RNAi screening procedure. After definition of the biological question and choice of the right cellular system, the read-out assay needs to be established. A pilot screen is performed to determine the robustness of the screening procedure and to identify possible optimization steps. After analysis of the pilot screen, genome-wide RNAi screenings can be performed, leading to a candidate list ranked according to the $z$-scores reflecting the strength of the phenotype. The candidates are then validated by retesting and secondary assays. 
Figure 1

Figure 1: Schematic view of RNAi in mammalian cells. Endogenous microRNAs (miRNA) and exogenous small hairpin RNAs (shRNA) are transcribed from DNA by RNA polymerase II. The resulting RNA hairpin is then processed by the nuclease Drosha, resulting in premiRNA/ processed shRNA which is transported from the nucleus into the cytoplasm via exportin 5 (Exp5). The RNA is further processed into $\sim 21 \mathrm{bp}$ fragments by the ribonuclease DICER. Synthetic short-interfering RNAs (siRNAs) resemble DICER processed double-stranded RNAs. These RNAs are incorporated into the RNA-induced silencing complex (RISC) where they are unwound and bind to complementary mRNA. Mature miRNAs preferentially bind to the $3^{\prime}$ UTR while most siRNAs target the open reading frame. In case of a perfect match, the mRNA is cleaved and degraded. In contrast, imperfect matching leads to translational repression and consequent mRNA destabilization $[9,10]$ $254 \times 190 \mathrm{~mm}$ (72 x 72 DPI) 
Figure 2

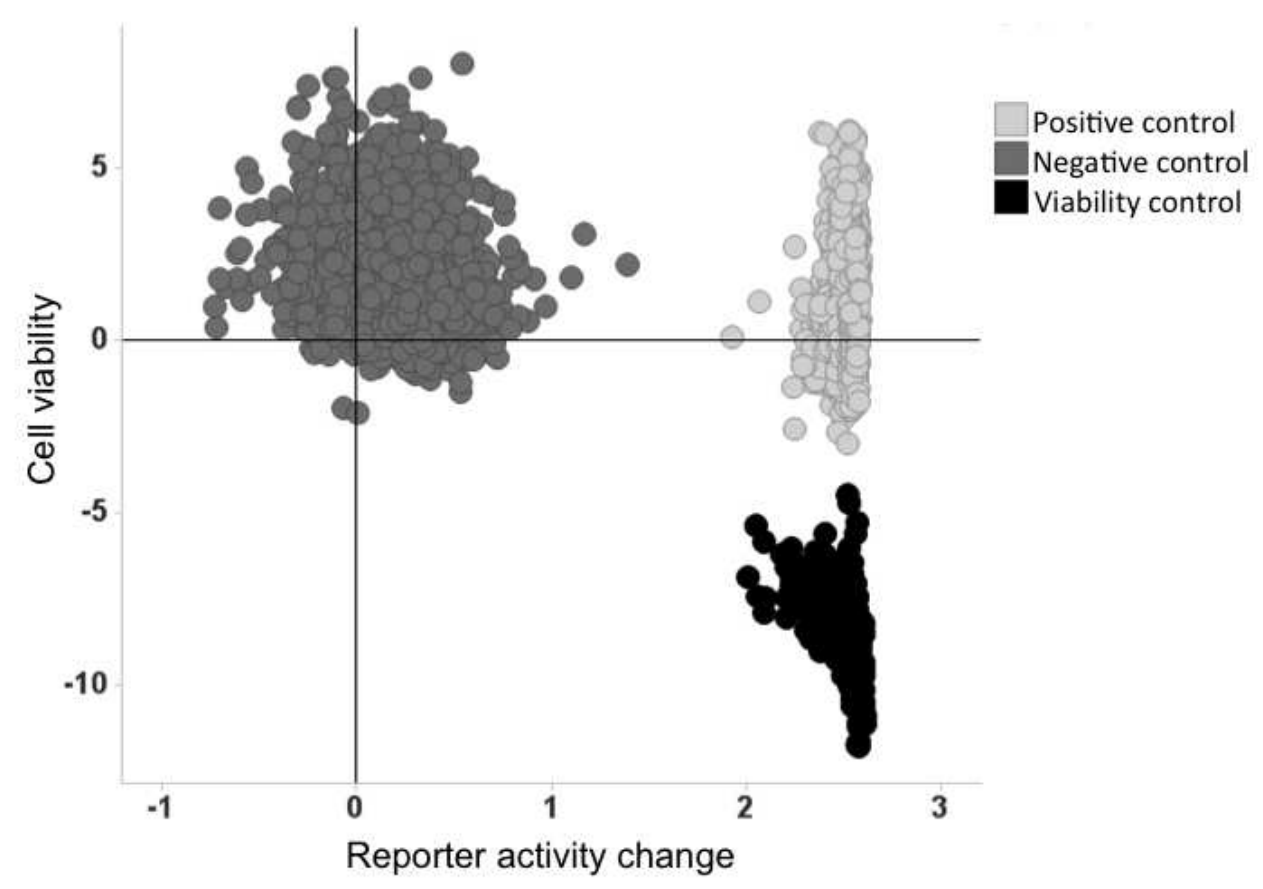

Figure 2: Scatter plot of average z-scores from a genome-wide RNAi screen. Luciferase reporter activity was measured using Mithras LB940 plate reader (Berthold Technologies) and TOPflash (TCF reporter plasmid). Cell viability was determined using Calcein-AM. siRNAs targeting $b$-catenin that result in reduction of wnt reporter activity were used as positive control. siRNAs targeting UBC cause loss of cell viability and were used as viability control. Non-targeting siRNAs were used as negative control. $254 \times 190 \mathrm{~mm}(72 \times 72 \mathrm{DPI})$ 
A

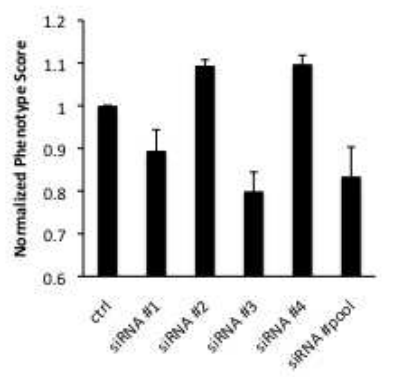

B

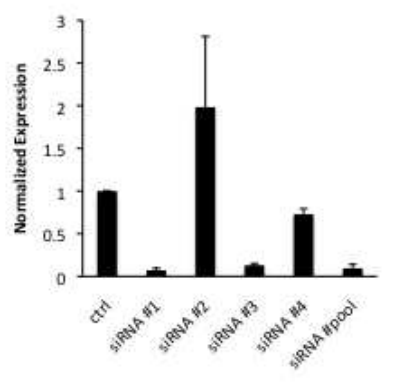

C

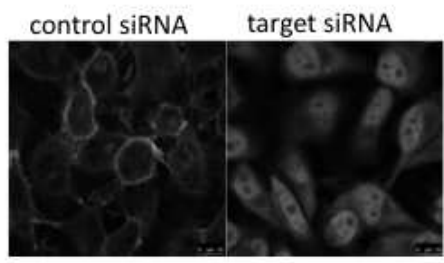

D

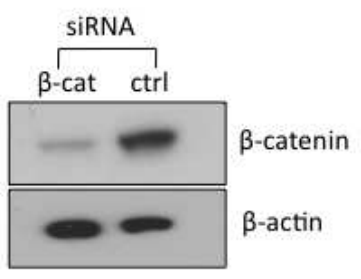

Figure 3: Hit validation with retests and secondary assays. A) Phenotype scores of control, single siRNAs and corresponding siRNA pool. B) Matching qRT-PCR validating knockdown of control, single siRNAs and corresponding siRNA pool. C) Nuclear translocation assay showing localization of the wnt pathway component $\beta$-catenin upon signal cascade activation by RNAi (scale bars equal $10 \mu \mathrm{m}$ ). D) Western blot analysis indicating knockdown of $\beta$-catenin on protein level. 
Figure 4 Definition of the biological question

Figure 4: Schematic view of the RNAi screening procedure. After definition of the biological question and choice of the right cellular system, the read-out assay needs to be established. A pilot screen is performed to determine the robustness of the screening procedure and to identify possible optimization steps. After analysis of the pilot screen, genome-wide RNAi screenings can be performed, leading to a candidate list ranked according to the z-scores reflecting the strength of the phenotype. The candidates are then validated by retesting and secondary assays. $190 \times 254 \mathrm{~mm}(72 \times 72 \mathrm{DPI})$ 